AperTO - Archivio Istituzionale Open Access dell'Università di Torino

\title{
Adult-onset autosomal recessive ataxia associated with neuronal ceroid lipofuscinosis type 5 gene (CLN5) mutations.
}

\section{This is the author's manuscript}

Original Citation:

Availability:

This version is available http://hdl.handle.net/2318/153157

since 2017-12-02T23:22:15Z

Published version:

DOI:10.1007/s00415-014-7553-y

Terms of use:

Open Access

Anyone can freely access the full text of works made available as "Open Access". Works made available under a Creative Commons license can be used according to the terms and conditions of said license. Use of all other works requires consent of the right holder (author or publisher) if not exempted from copyright protection by the applicable law. 


\section{(3) \\ UNIVERSITÀ DEGLI STUDI DI TORINO}

This is an author version of the contribution published on:

Questa è la versione dell'autore dell'opera:

[J Neurol. 2015 Jan;262(1):173-8. doi: 10.1007/s00415-014-7553-y]

The definitive version is available at:

La versione definitiva è disponibile alla URL:

[http://link.springer.com/article/10.1007\%2Fs00415-014-7553-y] 


\section{Adult-onset autosomal recessive ataxia associated with neuronal ceroid}

\section{lipofuscinosis type 5 gene (CLN5) mutations}

Cecilia Mancini, ${ }^{1 *}$ Stefano Nassani, ${ }^{2 *}$ Yiran Guo, ${ }^{3 *}$ Yulan Chen, ${ }^{4}$ Elisa Giorgio, ${ }^{1}$ Alessandro Brussino, ${ }^{1}$ Eleonora Di Gregorio, ${ }^{5}$ Simona Cavalieri, ${ }^{5}$ Nicola Lo Buono, ${ }^{1}$ Ada Funaro, ${ }^{1}$ Nicola Renato Pizio, ${ }^{2}$ Bruce Nmezi, ${ }^{6}$ Aija Kyttala ${ }^{7}$, Filippo Maria Santorelli, ${ }^{8}$ Quasar S. Padiath, ${ }^{6}$ Hakon Hakonarson, ${ }^{3,9}$ Hao Zhang, ${ }^{4}$ Alfredo Brusco, ${ }^{1,5}$

${ }^{1}$ University of Torino, Department of Medical Sciences, Italy

${ }^{2}$ Neurology Unit, Hospital of Lavagna, Italy

${ }^{3}$ Center for Applied Genomics, Children's Hospital of Philadelphia, Philadelphia, PA 19104, USA

${ }^{4}$ BGI-Shenzhen, Shenzhen, 518083, China

${ }^{5}$ Medical Genetics Unit, "Città della Salute e della Scienza" University Hospital, Torino, Italy

${ }^{6}$ Department of Human Genetics, Graduate School of Public Health, University of Pittsburgh, Pittsburgh, PA, USA

${ }^{7}$ National Institute for Health and Welfare (THL) Public Health Genomics Unit, FIN-00251 Helsinki, Finland.

${ }^{8}$ IRCCS Stella Maris, Pisa, Italy

${ }^{9}$ Department of Pediatrics, The Perelman School of Medicine, University of Pennsylvania, Philadelphia, PA 19104, USA

* Equal Contribution

Corresponding author: Alfredo Brusco, University of Torino, Department of Medical Sciences, via Santena 19, 10126, Torino, Italy; e-mail: alfredo.brusco@ unito.it; phone: 00390116334480; fax:00390116706582;

Keywords: CLN5, ceroid lipofuscinosis, hereditary ataxias, SCAR 


\begin{abstract}
Autosomal recessive inherited ataxias are a growing group of genetic disorders. We report two Italian siblings presenting in their mid-50s with difficulty in walking, dysarthria and progressive cognitive decline. Visual loss, ascribed to glaucoma, manifested a few years before the other symptoms. Brain MRI showed severe cerebellar atrophy, prevalent in the vermis, with marked cortical atrophy of both hemispheres. Exome sequencing identified a novel homozygous mutation (c.935G>A;p.Ser312Asn) in the ceroid neuronal lipofuscinosis type 5 gene (CLN5). Bioinformatics predictions and in vitro studies showed that the mutation was deleterious and likely affects ERlysosome protein trafficking. Our findings support CLN5 hypomorphic mutations cause autosomal recessive cerebellar ataxia, confirming other reports showing $C L N$ mutations are associated with adult-onset neurodegenerative disorders. We suggest $C L N$ genes should be considered in the molecular analyses of patients presenting with adult-onset autosomal recessive cerebellar ataxia.
\end{abstract}




\section{INTRODUCTION}

The hereditary ataxias are a highly genetically heterogeneous group of disorders phenotypically characterized by gait ataxia, incoordination of eye movements, speech, and hand movements, and usually associated with cerebellar atrophy. Autosomal dominant forms typically have adult-onset; conversely autosomal recessive ataxias usually have onset in childhood [10]. Clinically and neuroradiologically these latter diseases overlap with milder forms of Neuronal Ceroid Lipofuscinosis (NCLs), a group of progressive neurodegenerative disorders characterized by the intralysosomal accumulation in both neural and peripheral tissues of autofluorescent, electron-dense cytoplasmic lipopigments (bearing close resemblance to lipofuscin)[1]. Clinically, NCLs are characterized by a variable combination of visual impairment, cerebellar ataxia, drug-resistant progressive myoclonic epilepsy, behavioral disturbances, mental deterioration, and early death [17]. NCLs are mainly transmitted with an autosomal recessive inheritance, though rare autosomal dominantly inherited forms have been described $[11,13,23]$, and largely occur in infancy or preteen ages.

At present, fourteen NCL forms are recognized, with 13 disease genes (named $C L N$ ) identified and more than 400 mutations reported (NCL Mutation Database: www.ucl.ac.uk/ncl/mutation).

Here we describe an autosomal recessive form of adult-onset cerebellar ataxia associated with a novel CLN5 missense change in two siblings.

\section{MATERIALS AND METHODS}

We studied ATA-7-TO family originating from the North-West of Italy, in which the two affected sibling were born from first cousins parents. Genomic DNA was extracted from peripheral blood (Qiagen, Hilden, Germany) following the manufacturer instructions. Molecular testing was negative for SCA1, SCA2, and Friedreich Ataxia. Exome sequencing and data analysis was performed implementing a previously described procedure [9] (see supplement).

Validation of the mutation was performed by Sanger sequencing in all members of the family with 
primers designed to the exon 4 region of CLN5 (Reference sequence NM_006493, NP_006484.1). Informed consent was obtained from all participants, . The study is a retrospective case report that does not require ethics committee approval.

Human wild-type CLN5-pCMV (a.a. 1-407, CLN5-wt) and CLN5-pCMV carrying the Finnish major disease causing mutation p.Tyr392* (CLN5-fin) have previously been described [16]. The CLN5-Ser312Asn vector was generated by in vitro mutagenesis, using the Quick Change site directed mutagenesis kit (Stratagene, La Jolla, CA, USA).

HEK293 cells were grown overnight on coverslips coated with gelatin $0.1 \%$ in 24 -well chambers and cultivated in DMEM $10 \% \mathrm{FCS}$ at $37^{\circ} \mathrm{C}$ and in presence of $5 \% \mathrm{CO}_{2}$. Transient transfection with vectors containing CLN5-wt, CLN5-fin or CLN5-Ser312Asn cDNA was performed with Turbofect reagent (Thermo Fisher Scientific, Asheville, NC, USA) using the reported protocol [16] (see supplement).

\section{RESULTS}

The 55-year-old proband (III-6 in figure 1A) was a woman who presented with gait instability, dysarthria, and a mild cognitive deficit. Her past medical history had been unremarkable until she first sought neurological expert consultation after age 50 because of unsteady gait. Neurologic examination at age 58 was significant for a slight attention deficit, modest nystagmus with vertical component, dysarthric slurred speech, mild head tremor, and truncal ataxia. We also observed mild dysmetria and dysdiadochokinesia, an ataxic gait and posture, normal sensation, and brisk deep reflexes in the four limbs with normal plantar flexor response. Somatosensory evoked potentials, electroencephalogram (EEG), and nerve conduction velocities were all normal, as well as routine blood tests (including blood count, total cholesterol, alpha-fetoprotein and vitamin E levels) . Brain CT scan and MRI at age 58 showed a marked cerebellar atrophy (more evident in the vermis than the hemispheres) with a severe bilateral cortical atrophy - mainly parietal and temporal without focal lesions (Figure 1B, C). 
At age 52, three years before recognition of her neurological symptoms, the patient complained visual problems that were initially attributed to glaucoma. Ophthalmological examination at age 58 revealed a limited visual field in both eyes with a paracentral scotoma in the left eye. Fundoscopy disclosed a bilateral pale and excavated optic disc consistent with a severe galucoma but we could not exclude a previous lesion of the optic nerve.

At the age of 61 years, the patient showed a worsening of her dysarthria, could not walk without help, and showed a severe intentional tremor in the four limbs. Upon appropriate testing, including an age/education-adjusted Mini Mental State Examination (MMSE) score of 19.4/30, and a Montreal Cognitive Assessment score of 10/30, we also documented a more severe cognitive impairment with weakness especially in visual/spatial and executive tests, language, abstract symbolic reasoning and action planning. Conversely, time and space orientation, short term memory and calculation were relatively preserved.

Her elder brother (patient III-5 in figure 1A) was first examined when he was 61 years old. He presented with gait problems and dysarthria since age 56 with a slight worsening over the past five years. Neurological evaluation showed an ataxic-spastic gait, nystagmus in all directions, dysarthria with slurred speech, marked dysmetria in the lower limbs, and brisk and symmetric deep reflexes in the limbs. Muscle strength and tone, as well as sensation, were not affected. A mild cognitive deficit was also evident at clinical examination, but the patient refused further neuropsychological testing. As for her sister, case III-6, also had glaucoma. Brain MRI was not available.

We performed whole exome sequencing on III-5 and III-6 (71x and 68x coverage depth, respectively; sequencing statistics in Table S1). Assuming an autosomal recessive model of inheritance, we identified a single homozygous variant c.935G>A on chr13:77574815 in the CLN5 gene, changing a Ser312 to Asn (NM_006493, OMIM *608102). This mutation was confirmed by Sanger sequencing (Figure 1D), in homozygosis in both affected siblings and in heterozygosis in 
the unaffected brother III-4.

Serine 312 is a highly evolutionary conserved amino acid in vertebrates and it change was predicted to be deleterious using different bioinformatics tools (Table S2, figure S1). We evaluated the consequences of the p.Ser312Asn on CLN5 subcellular localization using immunofluorescence microscopy after HEK293 transfection (Figure 1E-G). Wild-type protein localized to lysosomal vesicles as expected [16], whereas both the CLN5-Ser312Asn and the CLN5-fin (Finnish mutation used as positive control) were retained in the Endoplasmic Reticulum (ER) compartment. Using cycloheximide, an inhibitor of cytoplasmic protein synthesis, we showed the complete disappearing of the fluorescence signal in cells carrying the CLN5-Ser312Asn indicating an intrinsic instability of the mutated proteins (Figure 1H-J).

\section{DISCUSSION}

Approximately 5\% of the $C L N$ mutations have been associated with adult-onset neurological phenotypes (from 17 to 43 yrs) divided into three different subtypes: Kufs diseases, characterized by progressive myoclonus epilepsy and cognitive decline (Type A), or behavioral anomalies, dementia, motor dysfunction, ataxia and extrapyramidal and suprabulbar signs (Type B) [4, 18]; adult NCLs which include autosomal dominant Parry disease due to DNJC5 mutations [13] and the recessive NCL type 11 associated with mutations in the progranulin gene [7](Table 1).

Ataxia is the first symptom in adult-onset Neuronal Ceroid Lipofuscinosis, often followed by rapid cognitive deterioration, epilepsy and retinal degeneration.

Using exome sequencing, we identified a homozygous c.935G>A (p.Ser312Asn) mutation in CLN5 in two adult siblings initially presenting ataxia. Both bioinformatics analysis and functional studies in HEK293 cells support the pathogenetic role of the mutation. While the wild-type CLN5 colocalize with lysosomes [16], the p.Ser312Asn mutant protein was retained in the ER and did not reach the lysosome, in analogy with p.Tyr392*, a previously well characterized CLN5 protein change causing an infantile-onset NCL in Finnish population. Therefore, our data further sustain the 
hypothesis that CLN5 mutations, including the one identified, impact the ER-lysosomal trafficking $[15,16]$.

Remarkably, both our cases had the onset of their neurological manifestations after 50 yrs in the form of cerebellar ataxia with mild cognitive impairment, and represent the most late-onset cases associated with $C L N$ mutations. Although features of glaucoma in both patients might be related to other processes, including aging, it is tempting to assume that ocular manifestations were part of the neurodegenerative process [24]. Most CLN5 mutations result in a classical disease with onset between 4-7 yrs, and few mutations are also associated with juvenile to early-adult onset. Three cases were described with onset at $17 \mathrm{yrs}$, carrying respectively the p.Tyr258Asp homozygous mutation [8], or the compound heterozygous p.Cys126Tyr / p.Tyr374Cys or p.Thr303CysfsX10 / p.Tyr374Cys mutations [24]. CLN5 disease-causing mutations are spread through the gene, and include missense, splicing and nonsense alterations (www.ucl.ac.uk/ncl/mutation). We hypothesize that the amino acid position and/or the chemical-physical change seen in our patients behaves as hypomorphic because it has a less severe impact on the protein function as compared to the other CLN5 variants.

TPP1, whose canonical mutations cause NCL2, has also been recently associated with autosomal recessive ataxia SCAR7 [20], suggesting the existence of a novel category of adult-onset diseases associated with $C L N$ mutations, presenting with cerebellar ataxia and progressive cognitive decline. These data indicate that CLN2 and CLN5 may be suspected in case of adult-onset autosomal recessive cerebellar ataxia, and foresees the identification of further $C L N$ involved in adult-onset phenotypes.

\section{ACKNOWLEDGMENTS}

We are grateful to the family members who participated in this study. We thank Dr. G.

D’Alessandro and Dr. E. Savin (S.C.d.U. Medical Genetics, "Città della Salute e della Scienza” 
Hospital, Torino, Italy) for suggestions with immunofluorescence analysis and Ms. G. Casale for technical help with transfection experiments.

\section{FUNDING AGENCIES.}

This work was funded by Associazione E. E. Rulfo, PRIN 2010_2011 (Grant 20108WT59Y) (to A. Brusco), a Research Grant from the Shenzhen Municipal Government of China (NO.CXZZ20130517144604091) to H. Jiang, funds from the University of Pittsburgh to Q. S. Padiath.

CONFLICT OF INTEREST: Yulan Chen and Hao Zhang are employees of BGI-Shenzhen. No further financial disclosure.

\section{ETHICAL STANDARDS}

This study has been performed in accordance with the ethical standards laid down in the 1964

Declaration of Helsinki. Written informed consent was obtained from the patient and approved by a local ethics committee. 


\section{FIGURE LEGENDS}

Figure 1. Pedigree, brain MRI, mutation and cellular analyses.

A. Pedigree of family ATA-7-TO suggested an autosomal recessive transmission due to parents consanguinity. B and C. Axial and sagittal T1-weighted brain resonance magnetic images in patient II-5 at 58 yrs. A marked cerebellar hemispheric and a more severe vermian atrophy is present. Supratentorial atrophy is also evident. D Mutation c.935G>A; p.Ser312Asn, affects a highly conserved amino acid (interspecies protein alignment is reported in figure S1). Panels E-J, localization of the p.Ser312Asn CLN5 mutant protein in HEK293 transfected cells. E-G. HEK293 cells transfected with human wild-type CLN5, CLN5-fin and CLN5-Ser312Asn mutants respectively. Immunostaining using rabbit antibody against CLN5 (1RmI-4) shows a diffuse punctate patter for wild-type protein consistent with its known lysosomal localization [16] (panel E). Both mutants show a diffuse reticular staining, compatible with a ER retention (panels F and G). Panels H-J illustrate the effect of cycloheximide treatment on CLN5 protein turnover (green). After three hours incubation with cycloheximide wild-type CLN5 maintains a lysosomal localization, while CLN5-fin and CLN5-Ser312Asn mutants completely disappear from ER, as demonstrated by counter-staining with the ER marker PDI (in red). 


\section{REFERENCES}

1. Anderson GW, Goebel HH, Simonati A (2013) Human pathology in NCL. Biochim Biophys Acta 1832:1807-1826

2. Arsov T, Smith KR, Damiano J, Franceschetti S, Canafoglia L, Bromhead CJ, Andermann E, Vears DF, Cossette P, Rajagopalan S, McDougall A, Sofia V, Farrell M, Aguglia U, Zini A, Meletti S, Morbin M, Mullen S, Andermann F, Mole SE, Bahlo M, Berkovic SF (2011) Kufs disease, the major adult form of neuronal ceroid lipofuscinosis, caused by mutations in CLN6. Am J Hum Genet 88:566-573

3. Benitez BA, Alvarado D, Cai Y, Mayo K, Chakraverty S, Norton J, Morris JC, Sands MS, Goate A, Cruchaga C (2011) Exome-sequencing confirms DNAJC5 mutations as cause of adult neuronal ceroid-lipofuscinosis. PLoS One 6:e26741

4. Berkovic SF, Carpenter S, Andermann F, Andermann E, Wolfe LS (1988) Kufs' disease: a critical reappraisal. Brain 111 ( Pt 1):27-62

5. Bertoni A, Giuliano P, Galgani M, Rotoli D, Ulianich L, Adornetto A, Santillo MR, Porcellini A, Avvedimento VE (2011) Early and late events induced by polyQ-expanded proteins: identification of a common pathogenic property of polYQ-expanded proteins. $\mathbf{J}$ Biol Chem 286:4727-4741

6. Cadieux-Dion M, Andermann E, Lachance-Touchette P, Ansorge O, Meloche C, Barnabe A, Kuzniecky RI, Andermann F, Faught E, Leonberg S, Damiano JA, Berkovic SF, Rouleau GA, Cossette P (2013) Recurrent mutations in DNAJC5 cause autosomal dominant Kufs disease. Clinical genetics 83:571-575

7. Canafoglia L, Morbin M, Scaioli V, Pareyson D, D'Incerti L, Fugnanesi V, Tagliavini F, Berkovic SF, Franceschetti S (2014) Recurrent generalized seizures, visual loss, and palinopsia as phenotypic features of neuronal ceroid lipofuscinosis due to progranulin gene mutation. Epilepsia 55:e56-59

8. Cannelli N, Nardocci N, Cassandrini D, Morbin M, Aiello C, Bugiani M, Criscuolo L, Zara F, Striano P, Granata T, Bertini E, Simonati A, Santorelli FM (2007) Revelation of a novel CLN5 mutation in early juvenile neuronal ceroid lipofuscinosis. Neuropediatrics 38:46-49

9. Guo Y, Prokudin I, Yu C, Liang J, Xie Y, Flaherty M, Tian L, Crofts S, Wang F, Snyder J, Donaldson C, Abdel-Magid N, Vazquez L, Keating B, Hakonarson H, Wang J, Jamieson RV (2014) Advantage of Whole Exome Sequencing over Allele-specific and Targeted Segment Sequencing, in Detection of Novel TULP1 Mutation in Leber Congenital Amaurosis. Ophthalmic Genet

10. Jayadev S, Bird TD (2013) Hereditary ataxias: overview. Genetics in medicine : official journal of the American College of Medical Genetics 15:673-683

11. Kollmann K, Uusi-Rauva K, Scifo E, Tyynela J, Jalanko A, Braulke T (2013) Cell biology and function of neuronal ceroid lipofuscinosis-related proteins. Biochim Biophys Acta 1832:1866-1881

12. Kousi M, Lehesjoki AE, Mole SE (2012) Update of the mutation spectrum and clinical correlations of over 360 mutations in eight genes that underlie the neuronal ceroid lipofuscinoses. Hum Mutat 33:42-63

13. Noskova L, Stranecky V, Hartmannova H, Pristoupilova A, Baresova V, Ivanek R, Hulkova H, Jahnova H, van der Zee J, Staropoli JF, Sims KB, Tyynela J, Van Broeckhoven C, Nijssen PC, Mole SE, Elleder M, Kmoch S (2011) Mutations in DNAJC5, encoding cysteine-string protein alpha, cause autosomal-dominant adult-onset neuronal ceroid lipofuscinosis. Am J Hum Genet 89:241-252

14. Ramadan H, Al-Din AS, Ismail A, Balen F, Varma A, Twomey A, Watts R, Jackson M, Anderson G, Green E, Mole SE (2007) Adult neuronal ceroid lipofuscinosis caused by deficiency in palmitoyl protein thioesterase 1. Neurology 68:387-388 
15. Savukoski M, Klockars T, Holmberg V, Santavuori P, Lander ES, Peltonen L (1998) CLN5, a novel gene encoding a putative transmembrane protein mutated in Finnish variant late infantile neuronal ceroid lipofuscinosis. Nat Genet 19:286-288

16. Schmiedt ML, Bessa C, Heine C, Ribeiro MG, Jalanko A, Kyttala A (2010) The neuronal ceroid lipofuscinosis protein CLN5: new insights into cellular maturation, transport, and consequences of mutations. Hum Mutat 31:356-365

17. Schulz A, Kohlschutter A, Mink J, Simonati A, Williams R (2013) NCL diseases - clinical perspectives. Biochim Biophys Acta 1832:1801-1806

18. Smith KR, Dahl HH, Canafoglia L, Andermann E, Damiano J, Morbin M, Bruni AC, Giaccone G, Cossette P, Saftig P, Grotzinger J, Schwake M, Andermann F, Staropoli JF, Sims KB, Mole SE, Franceschetti S, Alexander NA, Cooper JD, Chapman HA, Carpenter S, Berkovic SF, Bahlo M (2013) Cathepsin F mutations cause Type B Kufs disease, an adultonset neuronal ceroid lipofuscinosis. Hum Mol Genet 22:1417-1423

19. Smith KR, Damiano J, Franceschetti S, Carpenter S, Canafoglia L, Morbin M, Rossi G, Pareyson D, Mole SE, Staropoli JF, Sims KB, Lewis J, Lin WL, Dickson DW, Dahl HH, Bahlo M, Berkovic SF (2012) Strikingly different clinicopathological phenotypes determined by progranulin-mutation dosage. Am J Hum Genet 90:1102-1107

20. Sun Y, Almomani R, Breedveld GJ, Santen GW, Aten E, Lefeber DJ, Hoff JI, Brusse E, Verheijen FW, Verdijk RM, Kriek M, Oostra B, Breuning MH, Losekoot M, den Dunnen JT, van de Warrenburg BP, Maat-Kievit AJ (2013) Autosomal recessive spinocerebellar ataxia 7 (SCAR7) is caused by variants in TPP1, the gene involved in classic late-infantile neuronal ceroid lipofuscinosis 2 disease (CLN2 disease). Hum Mutat 34:706-713

21. van Diggelen OP, Thobois S, Tilikete C, Zabot MT, Keulemans JL, van Bunderen PA, Taschner PE, Losekoot M, Voznyi YV (2001) Adult neuronal ceroid lipofuscinosis with palmitoyl-protein thioesterase deficiency: first adult-onset patients of a childhood disease. Ann Neurol 50:269-272

22. Velinov M, Dolzhanskaya N, Gonzalez M, Powell E, Konidari I, Hulme W, Staropoli JF, Xin W, Wen GY, Barone R, Coppel SH, Sims K, Brown WT, Zuchner S (2012) Mutations in the gene DNAJC5 cause autosomal dominant Kufs disease in a proportion of cases: study of the Parry family and 8 other families. PLoS One 7:e29729

23. Warrier V, Vieira M, Mole SE (2013) Genetic basis and phenotypic correlations of the neuronal ceroid lipofusinoses. Biochim Biophys Acta 1832:1827-1830

24. Xin W, Mullen TE, Kiely R, Min J, Feng X, Cao Y, O'Malley L, Shen Y, Chu-Shore C, Mole SE, Goebel HH, Sims K (2010) CLN5 mutations are frequent in juvenile and lateonset non-Finnish patients with NCL. Neurology 74:565-571 


\begin{tabular}{|c|c|c|c|c|c|c|c|}
\hline $\begin{array}{c}\mathrm{NCL} \\
\text { category }\end{array}$ & GENE & $\begin{array}{l}\text { Inheri- } \\
\text { tance }\end{array}$ & Mutation & $\begin{array}{c}\text { Number } \\
\text { of } \\
\text { Cases }\end{array}$ & $\begin{array}{c}\text { Age } \\
\text { at } \\
\text { onset } \\
\text { (yrs) }\end{array}$ & Phenotype at onset & Ref \\
\hline \multirow{8}{*}{ 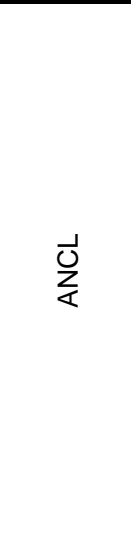 } & CLN1 (PPT) & AR & $\begin{array}{l}\text { p.Arg151* } \\
\text { p.Gly108Arg }\end{array}$ & 2 & $31-38$ & $\begin{array}{l}\text { Psychiatric symptoms followed by ataxia, visual, } \\
\text { verbal, and cognitive losses }\end{array}$ & [21] \\
\hline & CLN1 (PPT) & AR & $\begin{array}{l}\text { p.Arg151* } \\
\text { p.Cys45Tyr }\end{array}$ & 1 & 24 & n.a. & [14] \\
\hline & CLN4a (DNAJC5) & $\mathrm{AD}$ & p.Leu115Arg & 1 & 34 & Seizure, progressive dementia & [13] \\
\hline & CLN4b (DNAJC5) & $A D$ & p.Leu116del & 1 & 25 & $\begin{array}{l}\text { Behavioural anomalies, seizure dementia, speech } \\
\text { regression followed by ataxia }\end{array}$ & [13] \\
\hline & CLN5 & AR & $\begin{array}{l}\text { p.Cys } 126 \text { Tyr } \\
\text { p.Tyr374Cys }\end{array}$ & 1 & 17 & $\begin{array}{l}\text { Cognitive regression and visual loss followed by } \\
\text { seizure and motor difficulty }\end{array}$ & [24] \\
\hline & CLN5 & AR & $\begin{array}{l}\text { p. Tyr303Cysfs*10 } \\
\text { p.Tyr374Cys }\end{array}$ & 1 & 17 & $\begin{array}{l}\text { Motor difficulty followed by seizure, visual loss and } \\
\text { cognitive regression }\end{array}$ & [5] \\
\hline & CLN6 & AR & $\begin{array}{l}\text { p.Tyr93Met } \\
\text { p.Leu128Val }\end{array}$ & 1 & n.a. & n.a. & [12] \\
\hline & CLN11 (GRN) & $\mathrm{AR}$ & p.Thr272Serfs*10 & 2 & $22-23$ & Visual failure and convulsion followed by ataxia & {$[19]$} \\
\hline \multirow{3}{*}{ 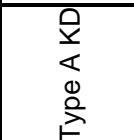 } & CLN4a (DNAJC5) & $A D$ & p.Leu116del & 1 & 26 & Behavioural anomalies, followed by seizures & [22] \\
\hline & CLN4a (DNAJC5) & $A D$ & p.Leu116del & 19 & $26-40$ & Myoclonus, Speech deterioration, Ataxia, Dementia & [6] \\
\hline & CLN4a (DNAJC5) & $A D$ & p.Leu115Arg & 1 & 43 & Myoclonus, Speech deterioration, Ataxia, Dementia & [6] \\
\hline
\end{tabular}




\begin{tabular}{|c|c|c|c|c|c|c|c|}
\hline & CLN4a (DNAJC5) & $A D$ & p.Leu116del & 10 & $28-33$ & $\begin{array}{l}\text { Myoclonus, Seizures, cognitive deterioration } \\
\text { followed by motor impairment }\end{array}$ & [13] \\
\hline & CLN6 & AR & p.Leu47Phe & 1 & 28 & $\begin{array}{l}\text { Myoclonus followed by ataxia and dementia. No } \\
\text { visual loss. }\end{array}$ & [2] \\
\hline & CLN6 & AR & p.Arg6Thr & 1 & 31 & $\begin{array}{l}\text { Seizures followed by myoclonus and dementia. No } \\
\text { visual loss. }\end{array}$ & [2] \\
\hline & CLN6 & AR & $\begin{array}{l}\text { p.Leu67Pro } \\
\text { p.Arg103GIn }\end{array}$ & 2 & $16-26$ & $\begin{array}{l}\text { Myoclonus followed by seizures and dementia. No } \\
\text { ataxia nor visual loss. }\end{array}$ & [2] \\
\hline & CLN6 & AR & p.Phe238Thr & 3 & $17-51$ & Myclonus, ataxia and cognitive decline & [2] \\
\hline & CLN6 & AR & $\begin{array}{c}\text { p.Tyr50* } \\
\text { p.Asn77Lys } \\
\text { p.Ser308Thr }\end{array}$ & 1 & n.a. & ( & [2] \\
\hline & CLN6 & AR & $\begin{array}{c}\text { p.Arg149His } \\
\text { p.Pro297Leufs }{ }^{*} 53\end{array}$ & 2 & $35-43$ & Seizure or ataxia followed by tremor and dementia & [2] \\
\hline & $C L N 4 b(D N A J C 5)$ & $\mathrm{AD}$ & p.Leu115Arg & 1 & 25 & Behavioral anomalies, dementia & {$[3]$} \\
\hline & CLN6 & $A D$ & p.Ala34Thr & 1 & 37 & Dementia followed by seizures & [2] \\
\hline 点 & CLN13 (CTSF) & $\mathrm{AR}$ & p.Gln321Arg & 1 & 24 & Seizures. Vision preserved & {$[18]$} \\
\hline$\stackrel{\infty}{\infty}$ & CLN13 (CTSF) & AR & $\begin{array}{l}\text { p.Gly458Ala } \\
\text { p.Ser480Leu }\end{array}$ & 2 & $22-32$ & $\begin{array}{l}\text { Progressive cerebellar syndrome, ataxia, } \\
\text { dysarthria. Vision preserved }\end{array}$ & [18] \\
\hline & CLN13 (CTSF) & AR & $\begin{array}{c}\text { p.Tyr231Cys } \\
\text { p.Ser319Leufs }{ }^{\star 27}\end{array}$ & 1 & 35 & $\begin{array}{l}\text { Cognitive decline, mild dysarthria, mild gait ataxia } \\
\text { with tremor. }\end{array}$ & [18] \\
\hline
\end{tabular}


Figure 1.

a

ATA-7-TO

I

II

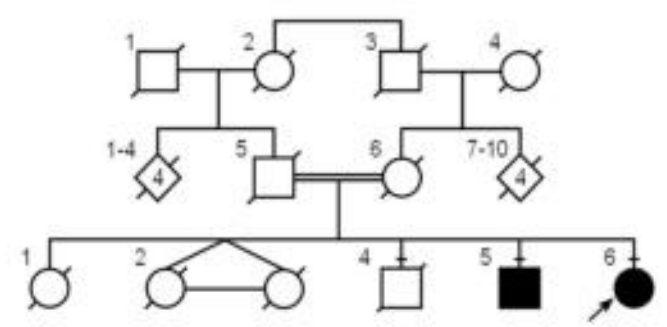

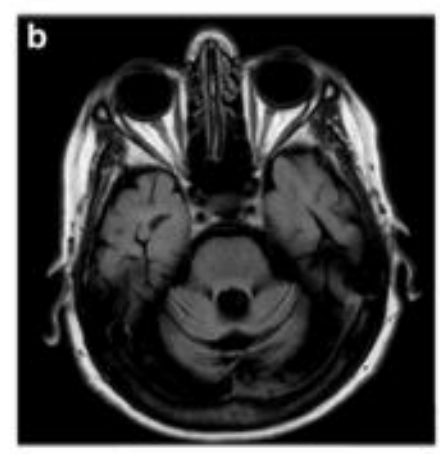
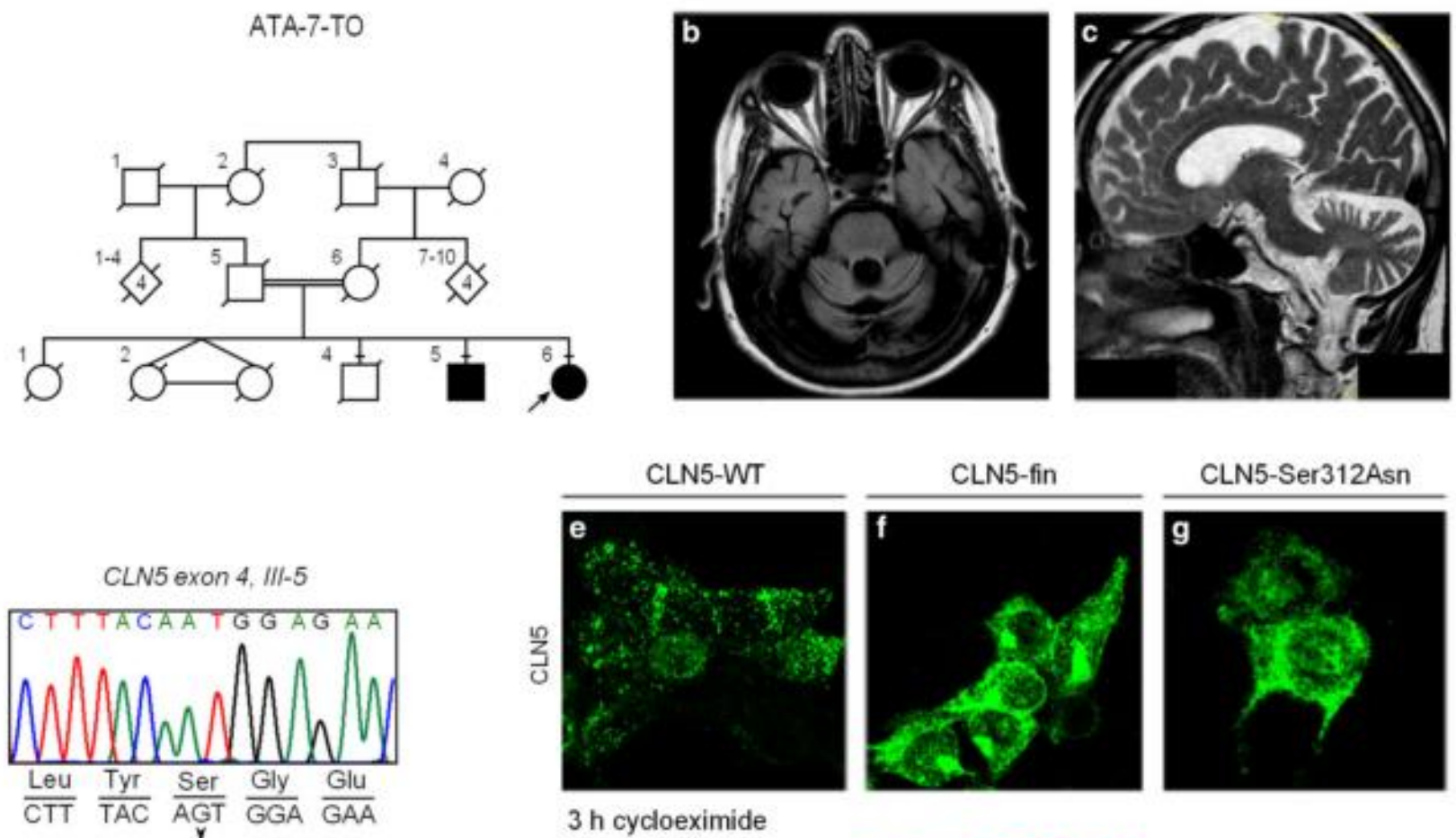

$\frac{\text { AAT }}{\text { Asn }}$

c. $935 G>A ; p$. Ser312Asn
CLN5-WT

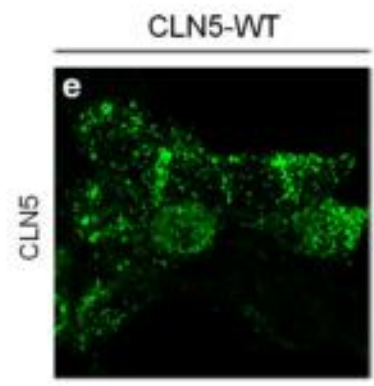

CLN5-fin

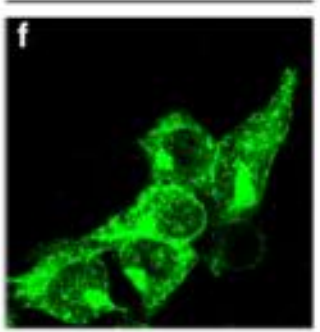

CLN5-Ser312Asn
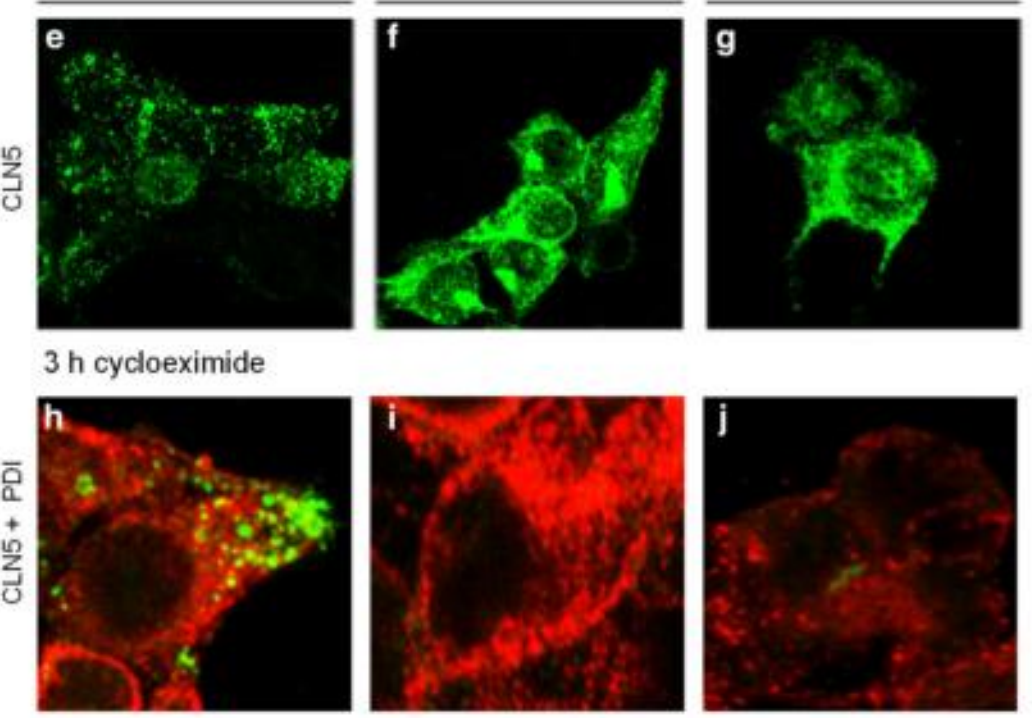


\section{Supplement}

\section{Materials and methods}

\section{Exome sequencing data analysis}

Briefly, we captured exonic regions from genomic DNA by using Agilent SureSelect Human All Exon kit, and performed pair-end sequencing on an Illumina HiSeq 2000. We followed two independent analysis workflows to perform sequencing read alignment, variant calling and variant annotation. In the first pipeline (P1), we employed Burrows-Wheeler alignment to map fastq files to the human reference genome (UCSC hg19)[11]. We called variants using Genome Analysis Tool Kit (GATK, version 1.4) [12] followed by functional annotation with Annovar [13] and SnpEff [14]. In the second pipeline (P2), we conducted alignment to UCSC hg19 by Short Oligonucleotide Analysis Package (SOAP, version2.21) [15], then used SOAPsnp (version 1.05) [16] to identify single nucleotide variants (SNVs) as well as GATK [12] to detect small insertion-deletions (indels). We annotated variants by BGI's self-developed scripts in the second pipeline.

We assumed an autosomal recessive inheritance model, and filtered variants generated in each pipeline, as described in supplement.

First we retained homozygous mutations shared by both affected individuals, and excluded variants that meet any of the following criteria: 1) intronic regions >20bp from exon boundaries; 2) synonymous changes; 3 ) minor allele frequency (MAF) $>0.5 \%$ in one of the following databases: dbSNP135 (http://www.ncbi.nlm.nih.gov/snp), 1000 Genomes Project ( $\mathrm{n}=1,092$ genotyped samples) (www.1000genomes.org), HapMap Project ( $\mathrm{n}=1,301$ genotyped samples) (http://hapmap.ncbi.nlm.nih.gov), NHLBI Exome Sequencing Project ( $\mathrm{n}=6,500$ exomes) (https://esp.gs.washington.edu/drupal/), CAG-CHOP ( $\mathrm{n}=669$ exomes), or BGI internal controls ( $\mathrm{n}$ $=1,414)$. We particularly considered variants close to splice sites and frameshift indels. Next, we prioritized the resulting variant list according to evolutionary conservation and filtered out regions with PhyloP [18] value $<0.95$; then retained variants predicted as "deleterious/damaging" by PolyPheN [19] and SIFT [20]. At last, we considered biological and clinical relevance of cerebellar 
ataxia for the identified candidates.

\section{Immunofluorescence}

Forty-eight hours after transfection, cells were fixed in ice-cold methanol for 3 min and then blocked with $0.5 \%$ bovine serum albumin (BSA) in phosphate buffered-saline (PBS) for 30 minutes. In the cycloeximide experiment, cells were treated with $50 \mu \mathrm{g} / \mathrm{ml}$ cycloheximide (SigmaAldrich, St. Louis, Missouri, USA) to stop protein synthesis for three hours prior to fixing. For colocalization studies we used primary antibodies against PDI for ER staining (1:200) (SigmaAldrich, St. Louis, Missouri, USA). CLN5 -antibody (1RmI-4) was used with dilutions previously reported in [21]. Primary and secondary antibodies were diluted in blocking buffer and incubated for $1 \mathrm{hr}$ respectively at $37^{\circ} \mathrm{C}$ or room temperature. Stained coverslips were visualized using Olympus confocal microscope (Olympus, Center Valley, PA, 18034, USA). 
Table S1. Sequencing summary statistics for the samples, as well as variant numbers called by CAG and BGI pipelines P1 and P2, respectively. Qualified variants mean those fall in exonic regions or at splicing donor/recipient sites.

\begin{tabular}{cccccccccc}
\hline Sample & $\begin{array}{c}\text { Family } \\
\text { relation } \\
\text { ship }\end{array}$ & $\begin{array}{c}\text { Total reads } \\
\text { mapped to } \\
\text { genome }(\mathrm{Mb})\end{array}$ & $\begin{array}{c}\text { Total data } \\
\text { on target } \\
\text { region }(\mathrm{Gb})\end{array}$ & $\begin{array}{c}\text { Mean depth } \\
\text { of target } \\
\text { region }\end{array}$ & $\begin{array}{c}\text { Coverage of } \\
\text { target region } \\
(\%)\end{array}$ & $\begin{array}{c}\text { Total SNV's } \\
\text { called (P1/P2) }\end{array}$ & $\begin{array}{c}\text { Qualified } \\
\text { SNV's } \\
\text { called } \\
(\mathrm{P} 1 / \mathrm{P} 2)\end{array}$ & $\begin{array}{c}\text { Total indel's } \\
\text { called } \\
(\mathrm{P} 1 / \mathrm{P} 2)\end{array}$ & $\begin{array}{c}\text { Qualifie } \\
\mathrm{d} \text { indel's } \\
\text { called } \\
(\mathrm{P} 1 / \mathrm{P} 2)\end{array}$ \\
\hline III-5 & $\begin{array}{c}\text { Affected } \\
\text { brother }\end{array}$ & 41.67 & 3.15 & 68.50 & 98.82 & $39,981 / 79,214$ & $\begin{array}{c}16,366 / 17,5 \\
67\end{array}$ & $6,388 / 5,926$ & $620 / 697$ \\
III-6 & $\begin{array}{c}\text { Affected } \\
\text { sister }\end{array}$ & 43.38 & 3.26 & 71.11 & 98.98 & $44,979 / 84,423$ & $\begin{array}{c}16,682 / 17,9 \\
80\end{array}$ & $7,060 / 6,237$ & $630 / 718$ \\
\hline
\end{tabular}


Table S2: In silico prediction of the p.Ser312Arg mutation on CLN5 protein

\begin{tabular}{|l|ll|l|}
\hline \multicolumn{1}{|c|}{ Software } & \multicolumn{1}{c|}{ Score } & \multicolumn{1}{c|}{ Predicted effect } & \multicolumn{1}{c|}{ Web site } \\
SIFT & 0 & Deleterious & http://sift.bii.a-star.edu.sg/ \\
Mutation T@ ster & 46 & Disease causing & www.mutationtaster.org/ \\
$\begin{array}{l}\text { MAPP } \\
\text { Polyphen 2 }\end{array}$ & $\begin{array}{l}0.001664 \\
\text { Bad }\end{array}$ & $\begin{array}{l}\text { Probably Damaging } \\
\text { http://mendel.stanford.edu/sidowlab/downloads/MAPP/index.html } \\
\text { www.genetics.bwh.harvard.edu/pph2/ }\end{array}$ \\
I-MUTANT & 2.0 & Reduced Stability & http://folding.biofold.org/i-mutant/i-mutant2.0.html \\
\hline
\end{tabular}

Figure S1. Evolutionary conservation of Serine 312 in vertebrates

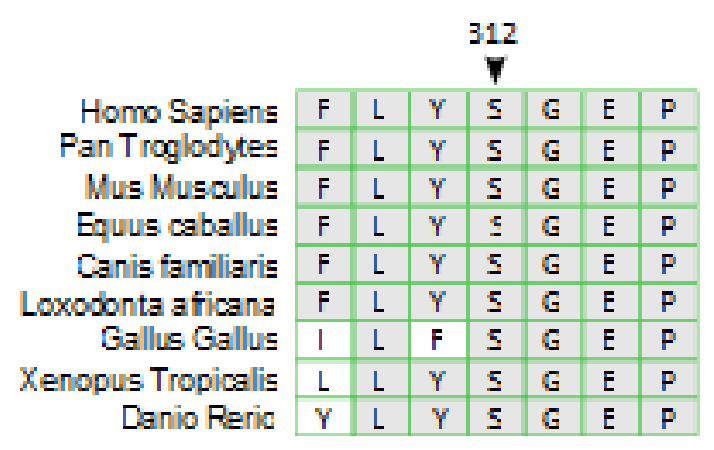

